\title{
Establish a Prediction Model for the Recurrence Time of Hormone Receptor Positive /human Epidermal Growth Factor Receptor 2-negative Breast Cancer
}

\section{Mengyu Hu}

Chongqing University Cancer Hospital https://orcid.org/0000-0002-6288-0897

\section{Huajie Xing}

Chongqing University Cancer Hospital

Huiping Li ( $\square$ huipingli2012@hotmail.com )

Peking University Cancer Hospital \& Institute https://orcid.org/0000-0002-3331-647X

Yaxin Liu

Beijing Cancer Hospital

Jiayang Zhang

Beijing Cancer Hospital

\section{Research article}

Keywords: breast cancer, metastasis, model of recurrence, HR positive/HER2 negative

Posted Date: August 10th, 2021

DOI: https://doi.org/10.21203/rs.3.rs-774230/v1

License: (c) (1) This work is licensed under a Creative Commons Attribution 4.0 International License.

Read Full License 


\section{Abstract}

Objectives

This study aimed to develop a model to predict recurrence time of hormone receptor-positive (HR+) /human epidermal growth factor receptor 2 negative (HER2-) breast cancer patients.

\section{Methods}

We included HR+ HER2- metastatic breast cancer (MBC) female patients who arrived at the Department of Breast Oncology in Peking University Cancer Hospital. Data were collected through consulting medical records. Patients were divided into early recurrence group and late recurrence group according to diseasefree survival (DFS). Predictors of recurrence time were identified and a nomogram was developed and validated using concordance index (C-index), AUC (area under the curve), and calibration plots.

Results

A total of 639 patients coming to the hospital between April 2007 and October 2019 were included. Median DFS was 50.0 months. 382 patients (59.8\%) were presented with early recurrence (DFS $\leq 5$ years), and 257 patients $(40.2 \%)$ were presented with late recurrence (DFS $>5$ years). A nomogram based on potentially associated clinicopathological factors was developed and validation results showed the nomogram was well-calibrated to predict recurrence time (AUC=0.703, C-index=0.697).

Conclusions

We have established a well-calibrated nomogram through 639 patients. HR+/HER2- BC patients with premenopausal status at initial diagnosis, less positive lymph nodes, lower level of Ki-67 were more common in late recurrence. The nomogram can predict the risk of late recurrence. Prospectively designed studies are needed to further validate our model.

\section{Introduction}

Breast cancer increased rapidly in China, the paper published in "Chinese journal of cancer research"showed that the age-standardized incidence rate was $36.1 / 100,000$ in 2018. ${ }^{(1)}$ Approximately 30 percent of early breast cancer $(B C)$ would appear recurrence ${ }^{(2,(3)}$. Clinicopathological characteristics such as hormone receptor (HR) status and number of metastatic lymph nodes, are used to predict recurrence risk as well as recurrence time. Among those characteristics, HR status is widely thought to be able to stratify early recurrence ( $\leq 5$ years) and late recurrence ( $₫ 5$ years) ${ }^{(4,(5)}$. For HR negative BC, recurrence rate reaches the highest level during the first two years after initial diagnosis, and drops rapidly to a low level afterwards. Most of the recurrence happens during the five years after initial diagnosis. However, for HR positive (HR+) BC, about 50 percent of recurrence happens after five-year adjuvant 
endocrine therapy ${ }^{(6,}(7,(8)$, and the recurrence risk tends to be stable at a low level after at least twenty years ${ }^{(3,}(9)$.

Estrogen receptor (ER), progesterone receptor (PR) or both are found in about 70 percent of all $B C$, and such tumors are considered $\mathrm{HR}+\mathrm{BC}{ }^{(10,(11)}$. Adjuvant therapy of early $\mathrm{BC}$ is important in improving prognosis, and adjuvant chemotherapy has been proved to significantly reduce recurrence rate of the first five years after diagnosis ${ }^{(12,(13)}$. However, $\mathrm{HR+/}$ human epidermal growth factor receptor 2 negative(HER2-) BC patients still suffer from high risk of late recurrence ${ }^{(14,(15)}$. Previous studies have shown that five-year endocrine therapy could reduce a third of late recurrence (15-year recurrence) ${ }^{(16)}$, and extending the time of adjuvant endocrine therapy to 10 years could reduce risk of late recurrence in the second decade after initial diagnosis $(17,(18,(19,(20,(21)$. Therefore, reliable prediction of recurrence time for HR+/ HER2- BC patients is necessary for appropriate treatment.

In foreign studies, researchers have explored the factors affecting recurrence time in HR+/ HER2- BC patients. For example, Yamashita et al found lager tumor size, more number of positive lymph nodes and higher histological grade were associated with early recurrence. After stratified by age or hormonal status, besides the factor mentioned before, PR status and Ki-67 expression level were associated with recurrence time as well ${ }^{(18)}$. Due to heterogeneity, prognosis of $B C$ is influenced by race, so study results abroad may not apply to Chinese. Therefore, this study is aimed to explore factors predicting recurrence time and construct a predictive model, providing reference for treatment of patients with HR+ /HER2- BC in China.

\section{Methods}

\section{Study population and design}

Patients diagnosed with histologically confirmed metastatic recurrence of HR+/HER2- BC who arrived at the Department of Breast Oncology in Peking University Cancer Hospital between April 2007 and October 2019 were included. Patients who were stage $\otimes$ at initial diagnosis or had other malignant tumors were excluded. The primary outcome was disease-free survival (DFS), which was defined as the time from initial diagnosis to first recurrence. Patients were stratefied into two groups-early recurrence group and late recurrence group, according to DFS. DFS $>5$ years was defined as late recurrence and DFS $\leq 5$ years was defined as early recurrence. Metastatic sites were identified by imaging examinations or rebiopsy. Multiple metastasis was defined as metastatic lesions involved more than one organ. Through consulting medical records, data about clinicopathological factors, adjuvant therapies and metastatic characteristics were collected. This study was conformed to guidelines of the 1996 Declaration of Helsinki and approved by the Ethics Committee of Peking University Cancer Hospital (No.2017KT40).

\section{IHC evaluation}


Expression of ER, PR, Ki-67 was evaluated by immunohistochemisty (IHC). HR was considered positive if there was $\geq 1 \%$ positive nuclear staining for either ER and/or PR. HER2 was considered positive as IHC score of $3+$, or $2+$ with fluorescent in situ hybridization showing gene amplification. HER2-positive patients were excluded from this study. According to expression level of ER and PR, HR was stratefied into four groups. Group 1 was defined as $1+$ or $₫ 25 \%$. Group 2 was defined as $2+$ or $25 \% \sim 50 \%$. Group 3 was defined as $3+$ or $50 \% \sim 75 \%$. Group 4 was defined as $\geq 75 \%$. Similarly, Ki- 67 was stratefied into four groups according to the expression level as well.

\section{Statistical methods}

Statistics analysis was performed using SPSS 23.0 and R 4.0.0 software. DFS was evaluated using the Kaplan-Meier log-rank test. Chi-square test was used to compare clinicopathological characteristics between early and late recurrence group. Multivariate analysis was performed using logistic regression model to identify independent factors influencing recurrence time. On the basis of potentially associated prognostic factors, a nomogram was constructed. The discrimination of the nomogram was evaluated by receiver operating characteristic $(\mathrm{ROC})$ curve and Concordance-index (C-index). Calibration was performed by bootstrapping with 1000 resamples. $P$-value $<0.05$ was considered as statistically significant.

\section{Results}

\section{Patient characteristics}

A total of 639 female patients who presented a metastatic recurrence of BC were included in the study. Most patients (91.1\%) were diagnosed after 2000/1/1. A description of patients in the study was given in Table 1. Median age at initial diagnosis of primary tumor was 47 years old with 263 patients $(41.2 \%)$ aged $\geq 50$ years old. A majority of patients $(61.0 \%)$ were premenopausal at initial diagnosis. Most patients $(528 / 639,83.0 \%)$ received adjuvant therapy after surgery, while $(108 / 639,17.0 \%)$ of them received neoadjuvant therapy before surgery. All patients received surgery and most of the surgery (93.6\%) was mastectomy including radical and simple mastectomy. 40 patients $(6.4 \%)$ had breast conserving surgery. Most common type of primary tumor $(513 / 539,84.1 \%)$ was invasive ductal carcinoma. Most of the patients received adjuvant/neoadjuvant chemotherapy (591/639, 92.5\%) and endocrine therapy $(505 / 639,79.0 \%)$, while 273 patients $(273 / 639,42.7 \%)$ received adjuvant radiotherapy. 382 patients $(59.8 \%)$ were presented with early recurrence, and 257 patients $(40.2 \%)$ were presented with late recurrence. Most common site of first metastasis was bone (297/639, 46.5\%). Second common site was lymph node $(253 / 639,39.6 \%)$. Lung and liver takes $24.7 \%(158 / 639)$ and $16.1 \%(103 / 639)$ of all metastatic sites respectively. Brain metastasis took 1.9\% (12/639) of all (Figure 1). Median DFS (Diseasefree survival) was 50.0 months (range 3.0-324.0 months). Proportion of recurrence over time is depicted in Figure 2. Approximately half of the patients $(335 / 639,52.4 \%)$ appeared recurrence at the fourth year. During the follow-up of first five-year, number of patients who appearing recurrence growed rapidly. At the 
fifth year of follow-up, 59.8\% (382/639) of patients appeared replase. Most $(557 / 639,87.2 \%)$ metastasis took place within ten years of follow-up.

\section{Univariate analysis}

Univariate survival analysis for DFS showed the following parameters as significant factors (Figure 3): age at diagnosis, hormonal status at diagnosis, treatment mode, histology of primary tumor, ScarffBloom-Richardson (SBR) grade, Ki-67, number of positive lymph nodes. Older age ( $\geq 50$ ), postmenopausal, higher SBR grade, higher level of Ki-67, more positive lymph nodes were associated with shorter DFS. In addition, patients receiving neoadjuvant therapy (most of those patients was presented as later stage) relapsed earlier than not receiving therapy before surgery $(P=0.003)$ in this study. Level of hormonal receptor and tumor size did not show significant impact on recurrence time. Even if tumor size did not show impact on DFS $(P=0.157)$, patients diagnosed with larger tumor size, tended to relapse earlier. Some variables (neoadjuvant/adjuvant chemo-/radio-therapy) need to be described taking possible confusing factors into account to understand their impact.

Neoadjuvant/adjuvant chemo-/radio-therapy seems to have no impact on recurrence time. Patients treated with chemotherapy or radiotherapy had more positive lymph nodes ( $P<0.001$ for both) than patients not treated with this type of treatment. Metastasis did not appear later in this group of patients even if they received treatment to delay recurrence.

Results comparing early recurrence and late recurrence group were shown in Table 2 and Figure 4. Patients with early recurrence took $59.8 \%$ (382/639) of all patients, which was more than patients with late recurrence (257/639). Comparied with late recurrence, there were more patients who were postmenopausal at initial diagnosis ( $42.6 \%$ vs $33.6 \%$ ), received neoadjuvant therapy ( $20.6 \%$ vs $11.7 \%)$, had higher level of Ki-67, had more positive lymph nodes, did not receive radiotherapy ( $46.6 \%$ vs $37.0 \%$ ) in early recurrent patients. There was no significant difference in proportion of patients receiving chemotherapy between two groups $(P=0.480)$, which was probably due to more positive lymph nodes in patients receiving chemotherapy as was mentioned before. Referring to first metastatic sites (Table 3), bone was most common in both groups. There were more liver metastasis ( $19.4 \%$ vs $11.3 \%, P=0.006)$, chest/skin/soft tissue metastasis $(28.8 \%$ vs $21.4 \%, P=0.036)$ in patients with early recurrence than late recurrence, while there were more pleura metastasis $(5.0 \%$ vs $12.8 \%, P<0.001)$ in patients with late recurrence than with early recurrence. There was no significant difference in bone metastasis, lymph node metastasis, lung metastasis and brain metastasis between two groups, and so was the number of first metastatic site.

\section{Multivariate analysis}

Referring to results of univariate analysis and clinical experience, logistic regression analysis was performed. Age at initial diagnosis, hormonal status at initial diagnosis, treatment mode, type of surgery, expression level of Ki-67, N stage, neo-/adjuvant chemotherapy, neo-/adjuvant endocrine therapy and adjuvant radiotherapy were included in logistic model, and the results were shown in Table 4.

Postmenopausal status, higher expression of Ki-67, more positive lymph nodes was more common in 
patients with early recurrence than late recurrence $(P=0.046,0.003,0.021$ respectively). Age of menopause in Chinese female is usually around 50 years old. To clarify whether there was interaction between age and hormonal status, interaction analysis was performed. The result indicated that there was no synergistic effect on recurrence time when combining age and hormonal status $(P=0.662)$.

\section{Construction and validation of the predictive model}

Logistic regression-based nomogram was constructed on the basis of potentially associated factors. Only patients with complete data of associated factors could be included to develop the nomogram. Because many patients lacked data on Ki-67 (Table 1), the factors mentioned before except expression level of Ki-67 were adopted to construct Nomogram $\otimes$ at first (Figure 5). There were 563 patients in the

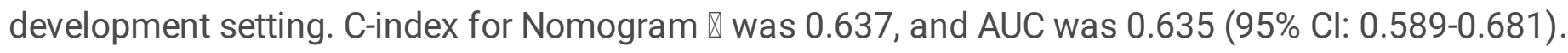
Internal validation was performed using bootstrap resampling method, and calibration curve was depicted in Figure 6. To optimize the model, considering the important role of Ki-67 in recurrence, Nomogram $\otimes$ was constructed with expression level of Ki-67 adopted at last(Figure 7). There were 357 patients in the development setting of Nomogram $\otimes$. C-index for Nomogram $\otimes$ was 0.697 , and AUC was 0.703 (95\% Cl: 0.643-0.763) (Figure 8). Calibration curve was depicted in Figure 9. The results in calibration curve showed absolute error and squared error were smaller in Nomogram $\otimes$ than that in

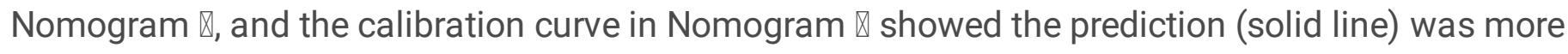

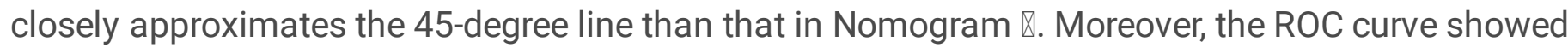
Nomogram $\otimes$ exhibited better discrimination to predict the probability of late recurrence than Nomogram \. From the nomogram, probablity of late recurrence of every patients could be easily obtained through calculating the total scores of clinicopathological factors.

\section{Discussion}

Late recurrence is not only observed in $\mathrm{HR}+\mathrm{BC}$, but also frequently found in many other solid tumors, such as thyroid, prostate cancer and melanoma. The mechanism of late recurrence is poorly understood yet. Some researchers think this is partly due to change of immune microenvironment in primary tumor and tumor dormancy $22,(23,(24,25,(26,(27)$. Although late recurrence remains a tough problem for HR+ BC patients, more and more evidence shows that extending time of endocrine therapy could reduce the risk of late recurrence ${ }^{(9)}$. Therefore, identifying patients at high risk of late recurrence and proposing a more appropriate treatment plan for them become a critical task. In this study, we found the features of late recurrence and some possible factors that might influence the recurrence time in HR+/HER2- patients, and constructed a model to predict the risk of late recurrence.

It is controversial whether hormonal status has impact on recurrence risk and recurrence time. Ditsatham et al found patients in premenopausal status had higher risk of recurrence than those in postmenopausal status ${ }^{(28)}$. In other studies, there was no difference in DFS between patients with late recurrence in premenopausal and postmenopausal status ${ }^{(29)}$, and there was no difference in hormonal status between patients with early and late recurrence ${ }^{(30)}$. In this study, hormonal status was an important factor 
affecting recurrence time in $\mathrm{BC}$ patients both in univariate and multivariate analysis. Patients in premenopausal status appeared relapse later than postmenopausal patients $(\mathrm{OR}=0.477, P=0.046)$. This phenomenon is probably due to comorbid condition, tumor burden and immune microenvironment ${ }^{(24)}$. As postmenopausal patients are older, the possibilities of having serious comorbid conditions are higher than younger premenopausal patients. And there might be a big difference in immune microenvironment between premenopausal and postmenopausal patients as well. As a result, although premenopausal patients has higher level of estrogen, they might appear recurrence later than postmenopausal patients. Thus the time of endocrine therapy for premenopausal patients should be extended.

In previous studies, some researchers found lymph node status could provide predictive information on late recurrence of $\mathrm{BC}(31,(32,(33)$. Risk of late recurrence especially distant recurrence increased when there were positive lymph nodes ${ }^{(34)}$. Some results revealed risk of late recurrence increased significantly when there were more than three positive lymph nodes $(29,(35)$. In this study, $>3$ positive lymph nodes was more frequently seen in patients with early recurrence than late recurrence. Meanwhile, even if there were less than 3 positive lymph nodes, quite a number of $(67.6 \%)$ patients appeared late recurrence. The results of this study testifies the influence of positive lymph nodes on recurrence time. This indicates that in future clinical work, patients with more than 3 positive lymph nodes should receive adjuvant radiotherapy and extended time of endocrine therapy to delay recurrence. On the other hand, for patients with small number of or without positive lymph nodes, the risk of late recurrence may not be that low, and other factors should be taken into consideration.

In biological studies, $\mathrm{Ki}-67$ is supposed to be an important prognostic factor. $\mathrm{Ki}-67$ is a monoclonal antibody, existing in all cell cycles except G0. It is a marker of cell proliferation, reflecting the aggressiveness of tumor cells. It is still under debated whether $\mathrm{Ki}-67$ is an independent prognostic factor. Some studies reported its role in predicting prognosis of $B C{ }^{(36,(37,(38,(39)}$, while other studies did not ${ }^{(40)}$. In a research on late recurrence of $\mathrm{BC}$, high level of $\mathrm{Ki}-67$ was associated with short DFS in univariate analysis, while only histological grade and lymph node metastasis were independent prognostic factors in multiple analysis ${ }^{(29)}$. In this study, there was significant statistical difference in the level of Ki-67 between early and late recurrence group, and high level of Ki-67 was more frequently seen in patients with early recurrence $(P=0.005)$. After excluding potential influence of other factors in multivariate analysis, $\mathrm{Ki}$ 67 was an independent factor affecting recurrence time of BC.

Influence of treatment mode on recurrence time was rarely discussed in previous studies. Akrami et al found chemotherapy before surgery was not related to recurrence time ${ }^{(41)}$. In this study, treatment mode, including neoadjuvant therapy and adjuvant therapy, was defined according to whether patients received treatment before surgery. Patients received neoadjuvant therapy to reduce tumor for surgery, and these patients were usually in poor condition at initial diagnosis. Our data testified this condition with the result that neoadjuvant therapy was more frequently seen in patients with early recurrence in univariate analysis $(20.6 \%$ vs $11.7 \%, P=0.003)$. Patients with later disease stage are more likely to undergo neoadjuvant therapy, which is why earlier recurrence occurred more in patients receiving neoadjuvant 
therapy. This phenomenon reflects the fact that characteristics of primary tumor greatly affect recurrence time, and even if patients receive treatment before surgery, the recurrence could not be delayed.

Akrami et al found adjuvant radiotherapy is a predictive factor of late recurrence ${ }^{(41)}$. In another study, recurrence time was not associated with adjuvant radiotherapy ${ }^{(30)}$. In univariate analysis of this study, adjuvant radiotherapy was more frequently seen in late recurrence group than in early recurrence group $(63.0 \%$ vs $53.4 \%)$. However, in multivariate analysis, there was no significant difference in radiotherapy between the two groups $(P=0.719)$. Because adjuvant radiotherapy is related to some clinical factors, such as breast-conserving surgery and positive lymph nodes. We further analyzed the relationship between type of surgery, lymph node metastasis and adjuvant radiotherapy. Adjuvant radiotherapy was not associated with type of surgery $(P=0.126)$, but was associated with positive lymph nodes $(P<0.001)$. Patients treated with adjuvant radiotherapy had more positive lymph nodes. Recurrence was not delayed even if they receive radiotherapy.

It has been demonstrated that breast tumor molecular subtypes are associated with site of metastasis.

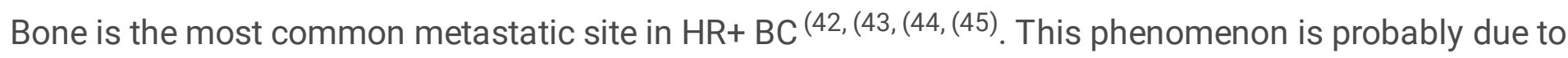
the important role of bone marrow in hematopoiesis. Dormant $\mathrm{BC}$ micrometastasis reside in specific bone marrow niches could transit from bone to circulation, thus causing metastasis and proliferation for tumor cells ${ }^{(46,(47)}$. In this study, no matter in early recurrence or late recurrence group, bone was the most common first metastatic site ( $44.0 \%$ and $50.2 \%$ respectively). On the other hand, liver and chest/skin/soft tissue metastasis were more frequently seen in early recurrence group (19.4\% vs $11.3 \%, 28.8 \%$ vs $21.4 \%$ ). Pleura metastasis was more frequently seen in late recurrence group $(12.8 \%$ vs $5.0 \%, P<0.001)$. There was no difference in lung metastasis between the two groups $(P=0.405)$. In some other studies, the relationship between recurrence time and metastatic site was a little different. For example, in a Japanese study, lung metastasis was more common in HR+/HER2- patients with late recurrence ${ }^{(48)}$. In another Japanese study, compared with early recurrence within 10 years, patients with late recurrence had less chest and liver metastasis and more lung and pleura metastasis ${ }^{(32)}$. Metastatic site is not only associated with primary tumor, but also has relationship with microenvironment and organ characteristics.

According to the results of univariate and multivariate analysis, we constructed a nomogram using $\mathrm{R}$ software and optimize it for better prediction value with a higher AUC value of 0.703 and a better calibration curve. Age, hormonal status, positive lymph nodes, Ki-67, treatment mode, type of surgery, radiotherapy, chemotherapy and endocrine therapy were included in this model. Doctors could easily identify patients with higher risk of late recurrence with the help of this model and give them more intensive treatment.

This study has some advantages. First, the sample size was large relatively thus ensuring reliability of the results. Second, this study included patients diagnosed in recent 20 years with a relatively long follow-up time and made a comprehensive review of the medical records allowing to clarify clinicopathological factors influencing recurrence time. Meanwhile, this study proposed a visual model helping better 
understand and calculate risk of late recurrence. This study has a few limitations as well. For example, this is a retrospective research with selection bias and incomplete data. Histological grade, an important prognostic factor, was not available in nearly half of the patients. The result on histological grade should be interpreted more carefully. Furthermore, we developed and validated a nomogram using data from the same center. We still need another population from different center to externally validate this nomogram.

Currently, more and more researches are focused on the role of genes and biomarkers in predicting late recurrence risk besides clinicopathological factors ${ }^{(49)}$, such as Oncotype DX, MammaPrint, BC Index and circulating tumor cell, which has the potential to optimize the candidates for extended endocrine therapy $(31,(50,51,(52,(53,(54,(55,(56),(57,(58)$. Combination of clinicopathological factors, genes and biomarkers may add significant prognostic information for late recurrence of $\mathrm{BC}$, and provide more useful reference for future work.

\section{Conclusion}

Our study showed that HR+/HER2- BC patients with premenopausal status at initial diagnosis, less positive lymph nodes, lower level of Ki-67 were more common in late recurrence. We developed a wellcalibrated nomogram predicting recurrence time of HR+/HER2- BC patients. The nomogram can predict the risk of late recurrence. Prospectively designed studies are needed to further validate our model.

\section{Declarations}

Ethics approval and consent to participate This study was conformed to guidelines of the 1996 Declaration of Helsinki and approved by the Ethics Committee of Peking University Cancer Hospital (No.2017KT40).

Consent for publication Not applicable.

Availability of data and materials Data in this article is available upon request.

Competing Interest The authors declare that they have no competing interests.

Funding There were no funding sources for this work.

Authors' contributions Huiping Li and Mengyu Hu contribute to conception and design of the study. Mengyu Hu and Huajie Xing analyzed and interpreted the patient data. Mengyu Hu was a major contributor in writing the manuscript. All authors read and approved the final manuscript.

Acknowledgements Not applicable.

\section{Author contribution:}

ES: Huiping Li, Mengyu Hu, 
FG :Mengyu Hu, Huajie Xing, Yaxin Liu, Jiayang Zhang, Huiping LI

All authors read and approved the final manuscript.

\section{References}

[1] Sun D, Cao M, Li H, et al. Cancer burden and trends in China: A review and comparison with Japan and South Korea. Chin J Cancer Res 2020;32:129-139.

[2] Saphner T, Tormey DC and Gray R. Annual hazard rates of recurrence for breast cancer after primary therapy. J Clin Oncol 1996;14:2738-46.

[3] Colleoni M, Sun Z, Price KN, et al. Annual Hazard Rates of Recurrence for Breast Cancer During 24 Years of Follow-Up: Results From the International Breast Cancer Study Group Trials I to V. J Clin Oncol 2016;34:927-35.

[4] Gonzalez-Angulo AM, Morales-Vasquez F and Hortobagyi GN. Overview of resistance to systemic therapy in patients with breast cancer. Adv Exp Med Biol 2007;608:1-22.

[5] Giampaolo Bianchini, Lajos Pusztai2, Thomas Karn3, et al. Proliferation and estrogen signaling can distinguish patients at risk for early versus late relapse among estrogen receptor positive breast cancers. Breast Cancer Research 2013, 15: R86.

[6] Thomas Saphner, Douglass C. Tormey, et al. Annual Hazard Rates of Recurrence for Breast Cancer After Primary Therapy. Journalof Clinical Oncology, 1996,14(10): 2738-2746.

[7] Sparano JA, Zhao F, Martino S, et al. Long-Term Follow-Up of the E1199 Phase III Trial Evaluating the Role of Taxane and Schedule in Operable Breast Cancer. J Clin Oncol 2015;33:2353-60.

[8] Snoj N, Paridaens R and Cufer T. Current controversies in extended adjuvant endocrine therapy for early breast cancer. Current Opinion in Oncology 2008;20:627-633.

[9] Chen X, Fan Y and Xu B. Distinct Characteristics and Metastatic Behaviors of Late Recurrence in Patients With Hormone Receptor-positive/Human Epidermal Growth Factor Receptor 2-negative Breast Cancer: A Single Institute Experience of More Than 10 Years. Clin Breast Cancer 2018;18:e1353-e1360.

[10] Murphy CG and Dickler MN. Endocrine resistance in hormone-responsive breast cancer: mechanisms and therapeutic strategies. Endocr Relat Cancer 2016;23:R337-52.

[11] Brufsky AM and Dickler MN. Estrogen Receptor-Positive Breast Cancer: Exploiting Signaling Pathways Implicated in Endocrine Resistance. Oncologist 2018;23:528-539.

[12] Early Breast Cancer Trialists' Collaborative G. Aromatase inhibitors versus tamoxifen in early breast cancer: patient-level meta-analysis of the randomised trials. Lancet 2015;386:1341-1352. 
[13] Palmieri C and Jones A. The 2011 EBCTCG polychemotherapy overview. Lancet 2012;379:390-2.

[14] Jatoi I, Anderson WF, Jeong JH, et al. Breast cancer adjuvant therapy: time to consider its timedependent effects. J Clin Oncol 2011;29:2301-4.

[15] Richman J and Dowsett M. Beyond 5 years: enduring risk of recurrence in oestrogen receptorpositive breast cancer. Nat Rev Clin Oncol 2019;16:296-311.

[16] Early Breast Cancer Trialists' Collaborative G. Effects of chemotherapy and hormonal therapy for early breast cancer on recurrence and 15-year survival: an overview of the randomised trials. Lancet 2005;365:1687-717.

[17] Goss PE, Ingle JN, Pater JL, et al. Late extended adjuvant treatment with letrozole improves outcome in women with early-stage breast cancer who complete 5 years of tamoxifen. $J$ Clin Oncol 2008;26:1948-55.

[18] Yamashita $\mathrm{H}$, Ogiya A, Shien $\mathrm{T}$, et al. Clinicopathological factors predicting early and late distant recurrence in estrogen receptor-positive, HER2-negative breast cancer. Breast Cancer 2016;23:830-843.

[19] Davies C, Pan H, Godwin J, et al. Long-term effects of continuing adjuvant tamoxifen to 10 years versus stopping at 5 years after diagnosis of oestrogen receptor-positive breast cancer: ATLAS, a randomised trial. The Lancet 2013;381:805-816.

[20] Jakesz R, Greil R, Gnant M, et al. Extended adjuvant therapy with anastrozole among postmenopausal breast cancer patients: results from the randomized Austrian Breast and Colorectal Cancer Study Group Trial 6a. J Natl Cancer Inst 2007;99:1845-53.

[21] Goss PE, Ingle JN, Pritchard Kl, et al. Extending Aromatase-Inhibitor Adjuvant Therapy to 10 Years. N Engl J Med 2016;375:209-19.

[22] Uhr JW and Pantel K. Controversies in clinical cancer dormancy. Proc Natl Acad Sci U SA 2011;108:12396-400.

[23] Gelao L, Criscitiello C, Fumagalli L, et al. Tumour dormancy and clinical implications in breast cancer. Ecancermedicalscience 2013;7:320.

[24] Takeshita T, Yan L, Asaoka M, et al. Late recurrence of breast cancer is associated with procancerous immune microenvironment in the primary tumor. Sci Rep 2019;9:16942.

[25] Ryan J.O. Dowling, Joseph A. Sparano, Pamela J. Goodwin, et al. Toronto Workshop on Late Recurrence in Estrogen Receptor Positive Breast Cancer Part 2: Approaches to Predict/Identify Late Recurrence, Research Directions. JNCI Cancer Spectr. 2019;3(4):pkz049. 
[26] Paul Goss, Alison L. Allan, David I. Rodenhiser, et al. New clinical and experimental approaches for studying tumor dormancy: does tumor dormancy offer a therapeutic target? APMIS.2008; 116: 552-568.

[27] Heindl A, Sestak I, Naidoo K, et al. Relevance of Spatial Heterogeneity of Immune Infiltration for Predicting Risk of Recurrence After Endocrine Therapy of ER+ Breast Cancer. JNCl: Journal of the National Cancer Institute 2018;110:166-175.

[28] Ditsatham C, Somwangprasert A, Watcharachan K, et al. Factors affecting local recurrence and distant metastases of invasive breast cancer after breast-conserving surgery in Chiang Mai University Hospital. Breast Cancer (Dove Med Press) 2016;8:47-52.

[29] Song F, Zhang J, Li S, et al. ER-positive breast cancer patients with more than three positive nodes or grade 3 tumors are at high risk of late recurrence after 5-year adjuvant endocrine therapy. Onco Targets Ther 2017;10:4859-4867.

[30] Chen Xuelian, Fan Ying, Xu Binghe. Clinicopathological features and prognosis of HER2】negative luminal囚type breast cancer patients with early and late recurrence. Chin J Oncol. 2016;38(6):448-453.

[31] Sestak I, Dowsett M, Zabaglo L, et al. Factors predicting late recurrence for estrogen receptorpositive breast cancer. J Natl Cancer Inst 2013;105:1504-11.

[32] Nishimura R, Osako T, Nishiyama Y, et al. Evaluation of factors related to late recurrence-later than 10 years after the initial treatment-in primary breast cancer. Oncology 2013;85:100-10.

[33] Payandeh M, Sadeghi M and Sadeghi E. Differences in Prognostic Factors between Early and Late Recurrence Breast Cancers. Asian Pac J Cancer Prev 2015;16:6575-9.

[34] Lee ES, Han W, Kim MK, et al. Factors associated with late recurrence after completion of 5-year adjuvant tamoxifen in estrogen receptor positive breast cancer. BMC Cancer 2016;16:430.

[35] Murata T, Jinno H, Takahashi M, et al. Clinicopathologic features of hormone-receptor-positive breast cancer patients with late recurrence. Breast J 2019;25:9-15.

[36] A E Pinto, S André, T Pereira, et al. Prognostic comparative study of S-phase fraction and Ki-67 index in breast carcinoma. J Clin Pathol. 2001;54:543-549.

[37] Trihia H, Murray S, Price K, et al. Ki-67 expression in breast carcinoma: its association with grading systems, clinical parameters, and other prognostic factors-a surrogate marker? Cancer 2003;97:1321-31.

[38] Daron J. Williams, Cynthia Cohen, w Mary Darrow, et al. Proliferation (Ki-67 and Phosphohistone H3) and Oncotype DX Recurrence Score in Estrogen Receptor-positive Breast Cancer. Appl Immunohistochem Mol Morphol. 2011;19(5):431-436. 
[39] Conforti F, Pala L, Pagan E, et al. Endocrine-responsive lobular carcinoma of the breast: features associated with risk of late distant recurrence. Breast Cancer Res 2019;21:153.

[40] Shirin Mojarad, Barbara Venturini, Patrizia Fulgenzi, et al. Prediction of Nodal Metastasis and Prognosis of Breast Cancer by ANN-based Assessment of Tumour Size and p53, Ki-67 and Steroid Receptor Expression. Anticancer Research 2013;33: 3925-3934.

[41] Akrami M, Arasteh P, Eghbali T, et al. Introducing novel and comprehensive models for predicting recurrence in breast cancer using the group LASSO approach: are estimates of early and late recurrence different? World J Surg Oncol 2018;16:185.

[42] Kennecke $\mathrm{H}$, Yerushalmi R, Woods R, et al. Metastatic behavior of breast cancer subtypes. J Clin Oncol 2010;28:3271-7.

[43] Kast K, Link T, Friedrich K, et al. Impact of breast cancer subtypes and patterns of metastasis on outcome. Breast Cancer Res Treat 2015;150:621-9.

[44] Xiao W, Zheng S, Yang A, et al. Breast cancer subtypes and the risk of distant metastasis at initial diagnosis: a population-based study. Cancer Manag Res 2018;10:5329-5338.

[45] Smid M, Wang Y, Zhang Y, et al. Subtypes of breast cancer show preferential site of relapse. Cancer Res 2008;68:3108-14.

[46] Trevor T. Price, Monika L. Burness, Ayelet Sivan, et al. Dormant breast cancer micrometastases reside in specific bone marrow niches that regulate their transit to and from bone. Sci Trans/ Med. 2016;8(340):340ra73.

[47] Fehm T, Becker S, Becker-Pergola G, et al. Presence of apoptotic and nonapoptotic disseminated tumor cells reflects the response to neoadjuvant systemic therapy in breast cancer. Breast Cancer Res 2006;8:R60.

[48] Ogiya A, Yamazaki K, Horii R, et al. Post-relapse survival in patients with the early and late distant recurrence in estrogen receptor-positive HER2-negative breast cancer. Breast Cancer 2017;24:473-482.

[49] Julia Foldi, Tess O'Meara, Michal Marczyk, et al. Defining Risk of Late Recurrence in Early-Stage Estrogen Receptor-Positive Breast Cancer: Clinical Versus Molecular Tools. J Clin Oncol. 2019;37(16):1365-1369..

[50] Sparano JA and Paik S. Development of the 21-gene assay and its application in clinical practice and clinical trials. J Clin Oncol 2008;26:721-8.

[51] Wolmark N, Mamounas EP, Baehner FL, et al. Prognostic Impact of the Combination of Recurrence Score and Quantitative Estrogen Receptor Expression (ESR1) on Predicting Late Distant Recurrence Risk in Estrogen Receptor-Positive Breast Cancer After 5 Years of Tamoxifen: Results From NRG 
Oncology/National Surgical Adjuvant Breast and Bowel Project B-28 and B-14. J Clin Oncol 2016;34:2350-8.

[52] Sestak I, Cuzick J, Dowsett M, et al. Prediction of late distant recurrence after 5 years of endocrine treatment: a combined analysis of patients from the Austrian breast and colorectal cancer study group 8 and arimidex, tamoxifen alone or in combination randomized trials using the PAM50 risk of recurrence score. J Clin Oncol 2015;33:916-22.

[53] Sgroi DC, Sestak I, Cuzick J, et al. Prediction of late distant recurrence in patients with oestrogenreceptor-positive breast cancer: a prospective comparison of the breast-cancer index (BCl) assay, 21-gene recurrence score, and IHC4 in the TransATAC study population. The Lancet Oncology 2013;14:1067-1076.

[54] Zhang Y, Schnabel CA, Schroeder BE, et al. Breast cancer index identifies early-stage estrogen receptor-positive breast cancer patients at risk for early- and late-distant recurrence. Clin Cancer Res 2013;19:4196-205.

[55] Sparano J, O'Neill A, Alpaugh K, et al. Association of Circulating Tumor Cells With Late Recurrence of Estrogen Receptor-Positive Breast Cancer: A Secondary Analysis of a Randomized Clinical Trial. JAMA Oncol 2018;4:1700-1706.

[56] Garcia-Murillas I, Schiavon G, Weigelt B, et al. Mutation tracking in circulating tumor DNA predicts relapse in early breast cancer. Sci Trans/ Med 2015;7:302ra133.

[57] Rohanizadegan M. Analysis of circulating tumor DNA in breast cancer as a diagnostic and prognostic biomarker. Cancer Genet 2018;228-229:159-168.

[58] Sestak I and Cuzick J. Markers for the identification of late breast cancer recurrence. Breast Cancer Res 2015;17:10.

\section{Tables}

Table 1. Patient characteristics $(n=639)$ 


\begin{tabular}{|c|c|c|c|}
\hline Characteristics & Number of patients & $\%$ & (No. of data available, \%) \\
\hline \multicolumn{4}{|l|}{ Age at diagnosis } \\
\hline Median(range) & $47(24,80)$ & - & $639,100 \%$ \\
\hline$<50$ years old & 376 & 58.8 & \\
\hline$\geq 50$ years old & 263 & 41.2 & \\
\hline Diagnosis period & & & $639,100 \%$ \\
\hline$>1985 / 1 / 1$ and $<2000 / 1 / 1$ & 57 & 8.9 & \\
\hline$\geq 2000 / 1 / 1$ and $\otimes 2011 / 1 / 1$ & 320 & 50.1 & \\
\hline$\geq 2011 / 1 / 1$ and $\otimes 2020 / 1 / 1$ & 262 & 41.0 & \\
\hline Hormonal status & & & $620,97.0 \%$ \\
\hline Premenopausal & 378 & 61.0 & \\
\hline Postmenopausal & 242 & 39.0 & \\
\hline Unknown & 19 & - & \\
\hline Body mass index & & & $626,98.0 \%$ \\
\hline Median(range) & $24.7(15.6,44.7)$ & - & \\
\hline Underweight & 17 & 2.7 & \\
\hline Normal & 253 & 40.4 & \\
\hline Overweight & 250 & 39.9 & \\
\hline Obese & 106 & 16.9 & \\
\hline Unknown & 13 & - & \\
\hline ECOG grade & & & $609,95.3 \%$ \\
\hline 0 & 468 & 76.8 & \\
\hline 1 & 107 & 17.6 & \\
\hline 2 & 22 & 3.6 & \\
\hline$\geq 3$ & 12 & 2.0 & \\
\hline Unknown & 30 & - & \\
\hline Treatment mode & & & $636,99.5 \%$ \\
\hline Adjuvant therapy & 528 & 83.0 & \\
\hline Neoadjuvant therapy & 108 & 17.0 & \\
\hline Unknown & 3 & - & \\
\hline
\end{tabular}




\begin{tabular}{|c|c|c|c|}
\hline Type of surgery & & & $622,97.3 \%$ \\
\hline Mastectomy & 582 & 93.6 & \\
\hline Breast conserving surgery & 40 & 6.4 & \\
\hline Unknown & 17 & - & \\
\hline Histology & & & $610,95.5 \%$ \\
\hline Invasive ductal & 513 & 84.1 & \\
\hline Invasive lobular & 44 & 7.2 & \\
\hline Other (mucoid, simple carcinoma, etc) & 53 & 8.7 & \\
\hline Unknown & 29 & - & \\
\hline Histological SBR grade & & & $339,53.1 \%$ \\
\hline G1 & 12 & 3.5 & \\
\hline G2 & 244 & 72.0 & \\
\hline G3 & 83 & 24.5 & \\
\hline Unknown & 300 & - & \\
\hline Hormonal receptor category & & & $576,90.1 \%$ \\
\hline $1+$ or $25 \%$ & 152 & 26.4 & \\
\hline $2+$ or $25 \% \sim 50 \%$ & 96 & 16.7 & \\
\hline $3+$ or $50 \% \sim 75 \%$ & 155 & 26.9 & \\
\hline$\geq 75 \%$ & 173 & 23.0 & \\
\hline Unknown & 63 & - & \\
\hline Ki-67 category & & & $387,60.4 \%$ \\
\hline $1+$ or $<25 \%$ & 181 & 46.8 & \\
\hline $2+$ or $25 \% \sim 50 \%$ & 134 & 34.6 & \\
\hline $3+$ or $50 \% \sim 75 \%$ & 54 & 14.0 & \\
\hline$\geq 75 \%$ & 18 & 4.7 & \\
\hline Unknown & 252 & - & \\
\hline Tumor size & & & $516,80.8 \%$ \\
\hline$\leq 2 \mathrm{~cm}$ & 178 & 34.5 & \\
\hline $2 \sim 5 \mathrm{~cm}$ & 279 & 54.1 & \\
\hline$\otimes 5 \mathrm{~cm}$ & 42 & 8.1 & \\
\hline
\end{tabular}




\begin{tabular}{|c|c|c|c|}
\hline $\mathrm{T} 4$ & 17 & 3.3 & \\
\hline Unknown & 123 & - & \\
\hline Lymph node & & & $587,91.9 \%$ \\
\hline 0 & 173 & 29.5 & \\
\hline $1 \sim 3$ & 180 & 30.7 & \\
\hline $4 \sim 9$ & 124 & 21.1 & \\
\hline$\geq 10$ & 110 & 18.7 & \\
\hline Unknown & 52 & - & \\
\hline Adjuvant/neoadjuvant chemotherapy & & & $639,100 \%$ \\
\hline Yes & 591 & 92.5 & \\
\hline No & 48 & 7.5 & \\
\hline Adjuvant/neoadjuvant endocrine therapy & & & $639,100 \%$ \\
\hline Yes & 505 & 79.0 & \\
\hline No & 134 & 21.0 & \\
\hline Adjuvant radiotherapy & & & $639,100 \%$ \\
\hline Yes & 273 & 42.7 & \\
\hline No & 366 & 57.3 & \\
\hline Recurrence time & & & $639,100 \%$ \\
\hline Early recurrence (DFS $\leq 5$ years) & 382 & 59.8 & \\
\hline Late recurrence (DFS $₫ 5$ years) & 257 & 40.2 & \\
\hline First metastatic sites & & & $639,100 \%$ \\
\hline Bone & 297 & 46.5 & \\
\hline Lymph nodes & 253 & 39.6 & \\
\hline Chest wall and skin & 165 & 25.8 & \\
\hline Lung & 158 & 24.7 & \\
\hline Liver & 103 & 16.1 & \\
\hline Pleura & 52 & 8.1 & \\
\hline Brain & 12 & 1.9 & \\
\hline Other & 71 & 11.1 & \\
\hline Disease-free survival (months) & & & $639,100 \%$ \\
\hline
\end{tabular}


ECOG, Eastern Cooperative Oncology Group \SBR, Scarff Bloom Richardson.

Table 2. Univariate analysis 


\begin{tabular}{|c|c|c|c|}
\hline \multirow[t]{2}{*}{ Variable } & Early recurrence: & Late recurrence: & \multirow[t]{2}{*}{$P$ value } \\
\hline & $\mathrm{DFS} \leq 5$ years $(\mathrm{N}=382)$ & DFS $>5$ years $(N=257)$ & \\
\hline Age at diagnosis & & & 0.150 \\
\hline$<50$ years & $216 \rrbracket 56.5 \% \rrbracket$ & $160 \rrbracket 62.3 \% \rrbracket$ & \\
\hline$\geq 50$ years & $166 \varangle 43.5 \% \rrbracket$ & $97 \rrbracket 37.7 \% \rrbracket$ & \\
\hline Hormonal status & & & 0.024 \\
\hline Premenopausal & $214 \llbracket 57.4 \% \bigotimes$ & $164 \llbracket 66.4 \% \rrbracket$ & \\
\hline Postmenopausal & $159 \llbracket 42.6 \% \rrbracket$ & $83 \rrbracket 33.6 \% \rrbracket$ & \\
\hline Unknown & 9 & 10 & \\
\hline Body mass index & & & 0.165 \\
\hline Underweight & $6 \rrbracket 1.6 \% \rrbracket$ & $11 \rrbracket 4.4 \% \rrbracket$ & \\
\hline Normal & $152 \rrbracket 40.3 \% \bigotimes$ & $101 \rrbracket 40.6 \% \rrbracket$ & \\
\hline Overweight & $151 \rrbracket 40.1 \% \rrbracket$ & $99 \llbracket 39.8 \% \rrbracket$ & \\
\hline Obese & $68 \rrbracket 18.0 \% \rrbracket$ & $38 \bigotimes 15.3 \% \rrbracket$ & \\
\hline Unknown & 5 & 8 & \\
\hline ECOG (performance status) & & & 0.128 \\
\hline 0 & $276 \bigotimes 75.2 \% \rrbracket$ & $192 \rrbracket 79.3 \% \rrbracket$ & \\
\hline 1 & $64 \rrbracket 17.4 \% \rrbracket$ & $43 \otimes 17.8 \% \rrbracket$ & \\
\hline 2 & $18 \rrbracket 4.9 \% \rrbracket$ & $4 \rrbracket 1.7 \% \rrbracket$ & \\
\hline$\geq 3$ & $9 \llbracket 2.5 \% \rrbracket$ & $3 \rrbracket 1.2 \% \rrbracket$ & \\
\hline Unknown & 15 & 15 & \\
\hline Treatment mode & & & 0.003 \\
\hline Adjuvant therapy & $301 \otimes 79.4 \% \rrbracket$ & $227 \llbracket 88.3 \% \rrbracket$ & \\
\hline Neoadjuvant therapy & $78 \rrbracket 20.6 \% \rrbracket$ & $30 \bigotimes 11.7 \% \rrbracket$ & \\
\hline Unknown & 3 & 0 & \\
\hline Type of surgery & & & 0.168 \\
\hline Mastectomy & $343 \varangle 92.5 \% \rrbracket$ & $239 \llbracket 95.2 \% \rrbracket$ & \\
\hline Breast conserving surgery & $28 \bigotimes 7.5 \% \rrbracket$ & $12 \rrbracket 4.8 \% \rrbracket$ & \\
\hline Unknown & 11 & 6 & \\
\hline Histology & & & 0.107 \\
\hline
\end{tabular}




\begin{tabular}{|c|c|c|c|}
\hline Invasive ductal & $324 \rrbracket 86.4 \% \rrbracket$ & $189 \otimes 80.4 \% \bigotimes$ & \\
\hline Invasive lobular & $25 \rrbracket 6.7 \% \rrbracket$ & $19 \llbracket 8.1 \% \rrbracket$ & \\
\hline Other & $26 \rrbracket 6.9 \% \rrbracket$ & $27 \rrbracket 11.5 \% \bigotimes$ & \\
\hline Unknown & 7 & 22 & \\
\hline Histological SBR grade & & & 0.170 \\
\hline G1 & $6 \rrbracket 2.5 \% \rrbracket$ & $6 \rrbracket 6.2 \% \square$ & \\
\hline G2 & $173 \otimes 71.5 \% \bigotimes$ & $71 \otimes 73.2 \% \square$ & \\
\hline G3 & $63 \rrbracket 26.0 \% \rrbracket$ & $20 \rrbracket 20.6 \% \rrbracket$ & \\
\hline Unknown & 140 & 160 & \\
\hline Hormonal receptor category & & & 0.127 \\
\hline $1+$ or $<25 \%$ & $87 \rrbracket 24.2 \% \rrbracket$ & $65 \rrbracket 30.1 \% 区$ & \\
\hline $2+$ or $25 \% \sim 50 \%$ & $57 \rrbracket 15.8 \% \bigotimes$ & $39 ه 18.1 \% \rrbracket$ & \\
\hline $3+$ or $50 \% \sim 75 \%$ & $96 \rrbracket 26.7 \% \rrbracket$ & $59 \rrbracket 27.3 \% \rrbracket$ & \\
\hline$\geq 75 \%$ & $120 \rrbracket 33.3 \% \rrbracket$ & $53 \varangle 9.2 \% \rrbracket$ & \\
\hline Unknown & 22 & 41 & \\
\hline Ki-67 category & & & 0.005 \\
\hline $1+$ or $<25 \%$ & $119 \rrbracket 41.9 \% \rrbracket$ & $62 \rrbracket 60.2 \% \bigotimes$ & \\
\hline $2+$ or $25 \% \sim 50 \%$ & $103 \rrbracket 36.3 \% \rrbracket$ & $31 \rrbracket 30.1 \% 区$ & \\
\hline $3+$ or $50 \% \sim 75 \%$ & $45 \rrbracket 15.8 \% \rrbracket$ & $9 \llbracket 8.7 \% \rrbracket$ & \\
\hline$\geq 75 \%$ & $17 \rrbracket 6.0 \% \rrbracket$ & $1 \otimes 1.0 \% \bigotimes$ & \\
\hline Unknown & 98 & 154 & \\
\hline Tumor size & & & 0.337 \\
\hline$\leq 2 \mathrm{~cm}$ & $108 \rrbracket 33.2 \% \rrbracket$ & $70 \rrbracket 36.6 \% \rrbracket$ & \\
\hline $2 \sim 5 \mathrm{~cm}$ & $181 \rrbracket 55.7 \% \rrbracket$ & $98 \rrbracket 51.3 \% \square$ & \\
\hline$>5 \mathrm{~cm}$ & $23 \otimes 7.1 \% \rrbracket$ & $19 \varangle 9.9 \% \rrbracket$ & \\
\hline T4 & $13 \rrbracket 4.0 \% \rrbracket$ & $4 \rrbracket 2.1 \% \rrbracket$ & \\
\hline Unknown & 57 & 66 & \\
\hline Lymph node & & & 0.003 \\
\hline 0 & $90 \rrbracket 25.1 \% \rrbracket$ & $83 \rrbracket 36.2 \% \square$ & \\
\hline $1 \sim 3$ & $108 \rrbracket 30.2 \% \rrbracket$ & $72 \rrbracket 31.4 \% \rrbracket$ & \\
\hline
\end{tabular}




\begin{tabular}{|c|c|c|c|}
\hline $4 \sim 9$ & $79 \llbracket 22.1 \% \rrbracket$ & $45 \rrbracket 19.7 \% \bigotimes$ & \\
\hline$\geq 10$ & $81 \rrbracket 22.6 \% \bigotimes$ & $29 \llbracket 12.7 \% \rrbracket$ & \\
\hline Unknown & 24 & 28 & \\
\hline Neo-/adjuvant chemotherapy & & & 0.480 \\
\hline Yes & $31 \llbracket 8.1 \% \rrbracket$ & $17 \rrbracket 6.6 \% \rrbracket$ & \\
\hline No & $351 \otimes 91.9 \% \rrbracket$ & $240 \otimes 93.4 \% \rrbracket$ & \\
\hline Neo-/adjuvant endocrine therapy & & & 0.172 \\
\hline Yes & $87 \rrbracket 22.8 \% \bigotimes$ & $47 \rrbracket 18.3 \% \bigotimes$ & \\
\hline No & $295 \rrbracket 77.2 \% \rrbracket$ & $210 \varangle 81.7 \% \rrbracket$ & \\
\hline Adjuvant radiotherapy & & & 0.016 \\
\hline Yes & $204 \rrbracket 53.4 \% \rrbracket$ & $162 \llbracket 63.0 \% \rrbracket$ & \\
\hline No & $178 \rrbracket 46.6 \% \rrbracket$ & $95 \llbracket 37.0 \% \bigotimes$ & \\
\hline
\end{tabular}

ECOG, Eastern Cooperative Oncology Group $\mathbb{S B R}$, Scarff Bloom Richardson; Cl, confidence interval; HR, hazard ratio

Table 3. First metastatic sites of the patients

\begin{tabular}{|c|c|c|c|}
\hline \multirow[t]{2}{*}{ Variable } & Early recurrence & Late recurrence & \multirow[t]{2}{*}{$P$ value } \\
\hline & DFS $\leq 5$ years $₫ N=382 \rrbracket$ & DFS $>5$ years $\llbracket N=257 \rrbracket$ & \\
\hline \multicolumn{4}{|l|}{ First metastatic site ${ }^{*}$} \\
\hline Bone & $168 \rrbracket 44.0 \% \rrbracket$ & $129 \llbracket 50.2 \% \bigotimes$ & 0.122 \\
\hline Lymph node & $148 \rrbracket 38.7 \% \rrbracket$ & $105 \rrbracket 40.9 \% \bigotimes$ & 0.592 \\
\hline Chest/skin/soft tissue & $110 \rrbracket 28.8 \% \rrbracket$ & $55 \rrbracket 21.4 \% \rrbracket$ & 0.036 \\
\hline Lung & $90 \rrbracket 23.6 \% \rrbracket$ & $68 \rrbracket 26.5 \% \rrbracket$ & 0.405 \\
\hline Liver & $74 \rrbracket 19.4 \% \bigotimes$ & $29 \otimes 11.3 \% \rrbracket$ & 0.006 \\
\hline Brain & $9 \llbracket 2.4 \% \rrbracket$ & $3 \otimes 1.2 \% \rrbracket$ & 0.278 \\
\hline Pleura & $19 \rrbracket 5.0 \% \rrbracket$ & $33 \rrbracket 12.8 \% \rrbracket$ & $₫ 0.001$ \\
\hline Number of first metastatic sites & & & 0.222 \\
\hline Single & $212 \rrbracket 55.5 \% \rrbracket$ & $130 \rrbracket 50.6 \% \rrbracket$ & \\
\hline Multiple & $170 \rrbracket 44.5 \% \rrbracket$ & $127 \rrbracket 49.4 \% \rrbracket$ & \\
\hline
\end{tabular}


${ }^{*}$ There might be more than one site.

Table 4. Multivariate logistic regression analysis 


\begin{tabular}{|c|c|c|c|}
\hline variable & $\mathrm{OR}$ & $95 \% \mathrm{Cl}$ & $P$ value \\
\hline \multicolumn{4}{|l|}{ Age at diagnosis } \\
\hline$\nabla 50$ years & 1 & 1 & \\
\hline$\geq 50$ years & 1.769 & $0.874-3.581$ & 0.113 \\
\hline \multicolumn{4}{|l|}{ Hormonal status } \\
\hline Premenopausal & 1 & 1 & \\
\hline Postmenopausal & 0.477 & $0.230-0.987$ & 0.046 \\
\hline \multicolumn{4}{|l|}{ Treatment mode } \\
\hline Adjuvant therapy & 1 & 1 & \\
\hline Neoadjuvant therapy & 0.639 & $0.330-1.237$ & 0.184 \\
\hline \multicolumn{4}{|l|}{ Type of surgery } \\
\hline Mastectomy & 1 & 1 & \\
\hline Breast conserving surgery & 0.348 & $0.093-1.298$ & 0.116 \\
\hline Ki-67 category & & & 0.003 \\
\hline $1+$ or $<25 \%$ & 1 & 1 & \\
\hline $2+$ or $25 \% \sim 50 \%$ & 0.483 & $0.278-0.840$ & 0.010 \\
\hline $3+$ or $50 \% \sim 75 \%$ & 0.343 & $0.145-0.809$ & 0.015 \\
\hline$\geq 75 \%$ & 0.077 & $0.009-0.617$ & 0.016 \\
\hline Lymph node & & & 0.021 \\
\hline 0 & 1 & 1 & \\
\hline $1 \sim 3$ & 0.742 & $0.384-1.434$ & 0.375 \\
\hline $4 \sim 9$ & 0.479 & $0.216-1.063$ & 0.070 \\
\hline$\geq 10$ & 0.235 & $0.091-0.607$ & 0.003 \\
\hline \multicolumn{4}{|l|}{ Adjuvant radiotherapy } \\
\hline Yes & 1 & 1 & \\
\hline No & 0.892 & $0.479-1.663$ & 0.719 \\
\hline \multicolumn{4}{|l|}{ Neo-/adjuvant chemotherapy } \\
\hline Yes & 1 & 1 & \\
\hline No & 0.546 & $0.181-1.652$ & 0.284 \\
\hline
\end{tabular}


$1 \quad 1$

No

0.601

$0.279-1.295$

0.194

$\mathrm{OR}<1$ suggests there was more risk in early recurrence (DFS $\leq 5$ years) than late recurrence (DFS $>5$ years). Otherwise there was less risk in early recurrence than late recurrence.

\section{Figures}

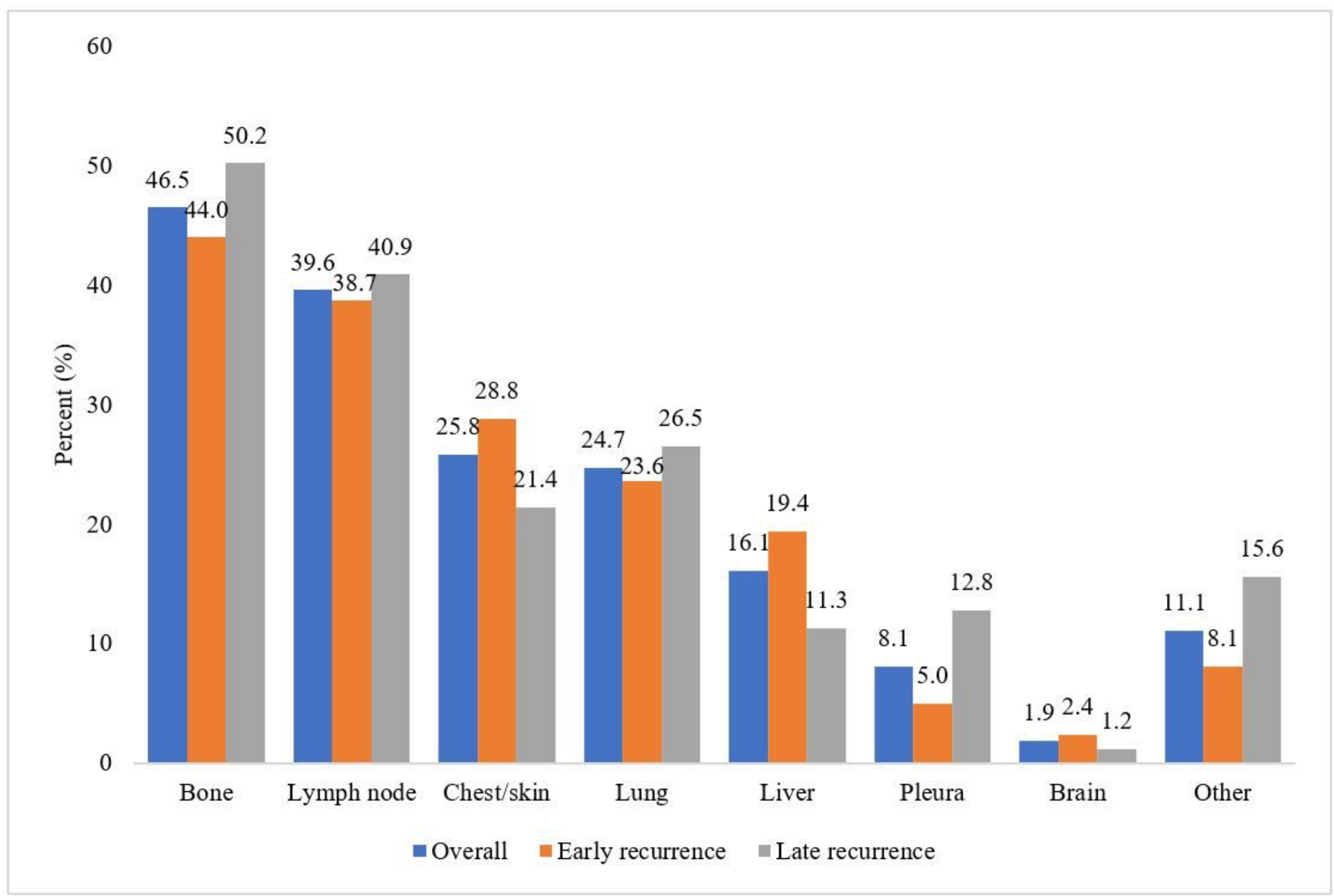

\section{Figure 1}

First metastatic sites of patients. Most common site of first metastasis was bone. Second common site was lymph node. There were more live metastasis (19.4\% vs $11.3 \%, \mathrm{P}=0.006)$, chest/skin/soft tissue metastasis $(28.8 \%$ vs $21.4 \%, \mathrm{P}=0.036)$ in patients with early recurrence than late recurrence, while there were more pleura metastasis $(5.0 \%$ vs $12.8 \%, P<0.001)$ in patients with late recurrence than with early recurrence. 


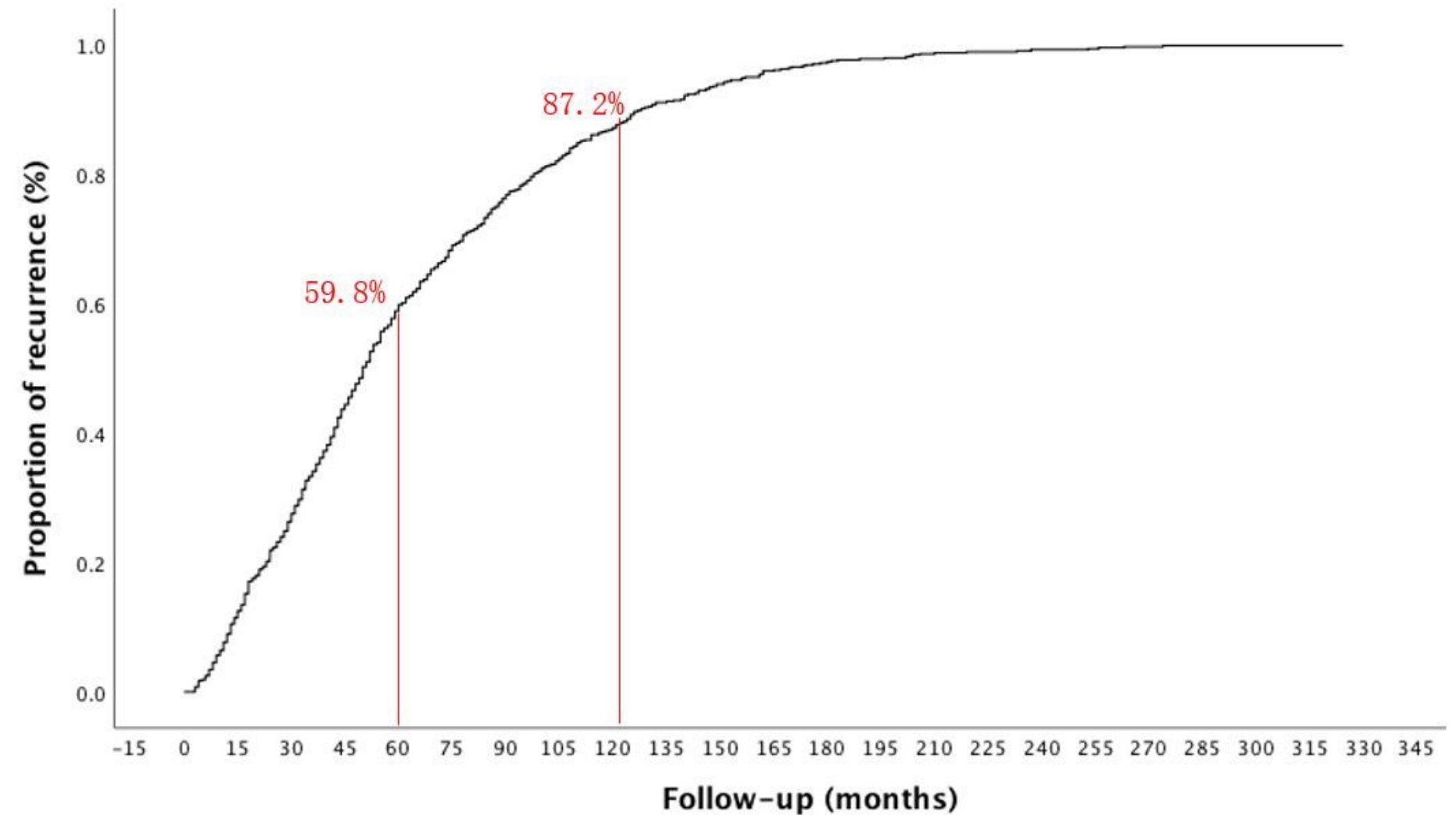

Figure 2

Proportion of recurrence over time of all patients. Half of the patients appeared recurrence at the fourth year. At the fifth year of follow-up, $59.8 \%$ of patients appeared replase. $87.2 \%$ of all recurrence took place in ten years of follow-up. 

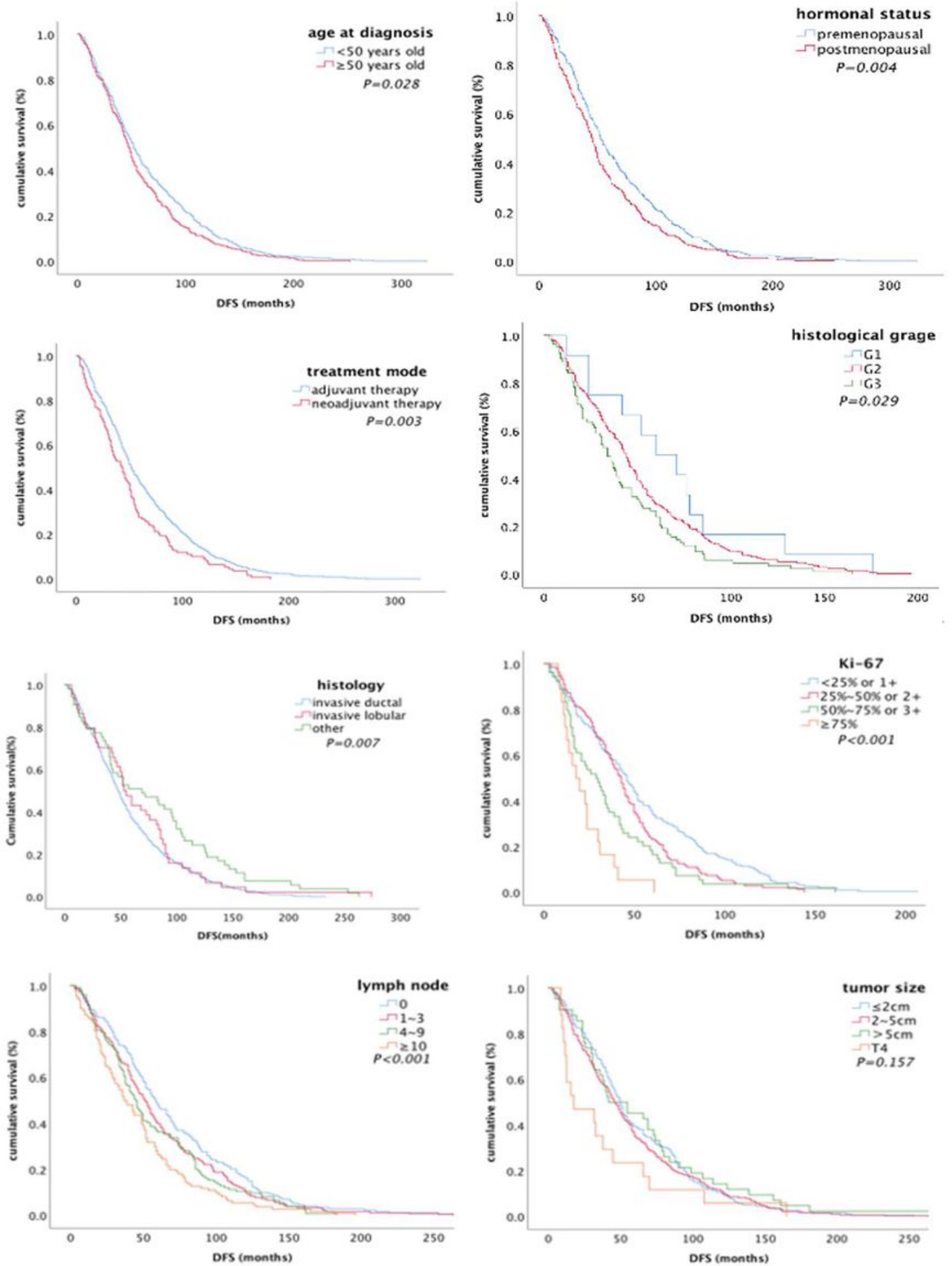

\section{Figure 3}

Kaplan-Meier curves for recurrence-free survival. Univariate survival analysis for DFS showed the following parameters as significant factors: age at diagnosis, hormonal status at diagnosis, treatment mode, histology of primary tumor, SBR grade, Ki-67, number of positive lymph nodes. 


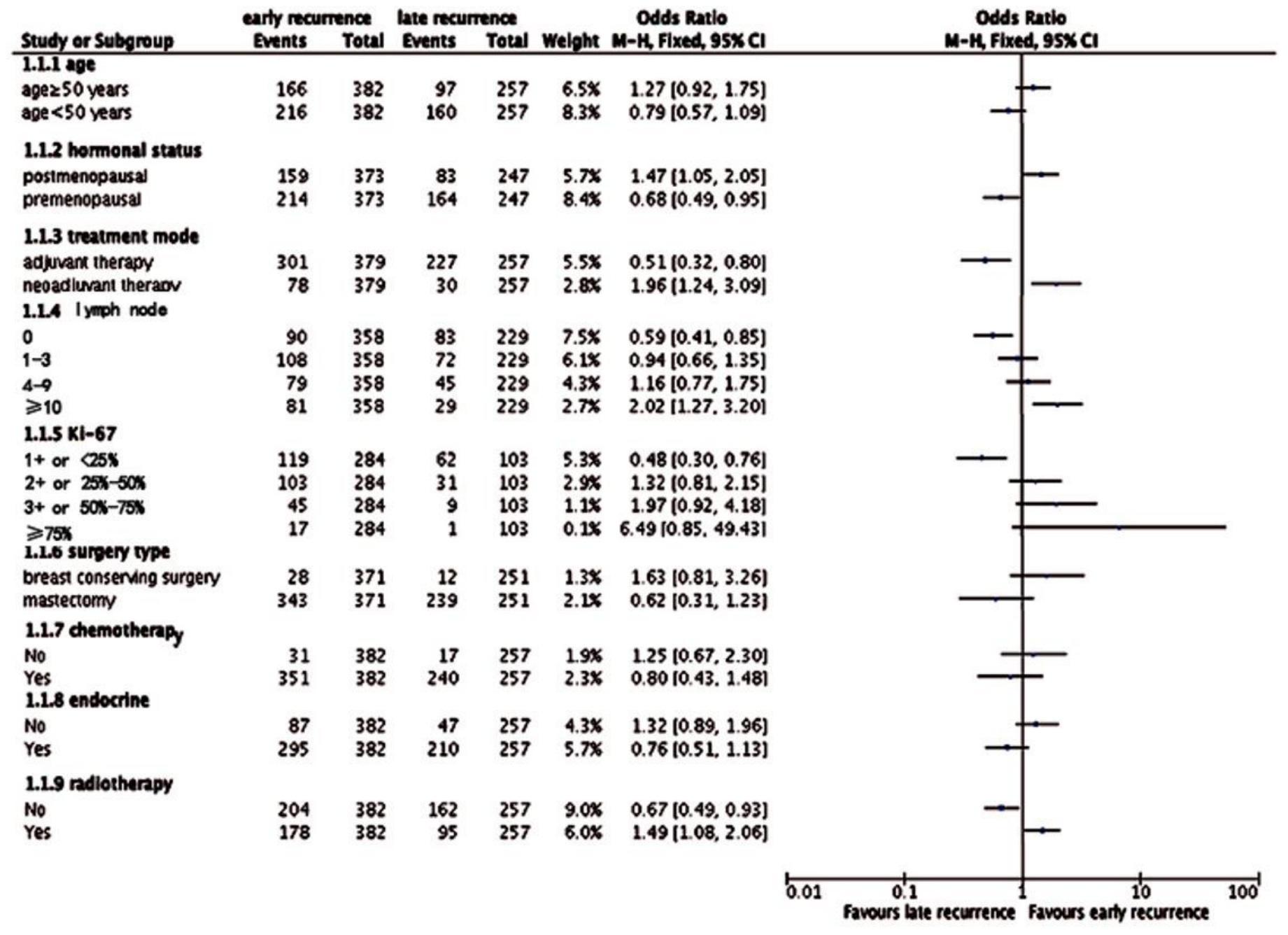

Figure 4

Forrest plot in univariate analysis. Premenopausal, adjuvant therapy, less positive lymph nodes, lower level of Ki-67, not receiving radiotherapy were more common in late recurrence group. 
Points

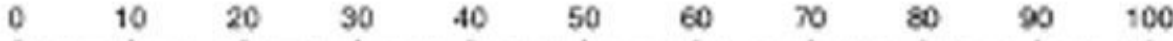

\section{Poims}

age

$\geq 50$

menopausal

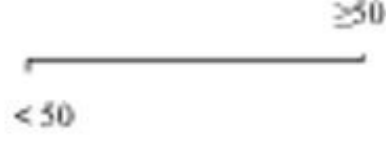

premenopausal

postmxenopausal

lymph_node

4.9

0

$\underset{10 \quad 1-3}{2+10}$

treatment_modo

adjuvant thenay

neo-adjuvart therapy

surgery_type

mastecoomy

breast-couserving surgery

no

radiotherapy

yes

yes

chemotherapy

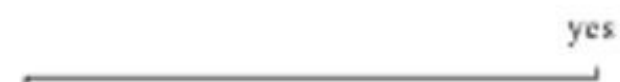

no

endocrine

yes

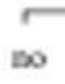

Total Points

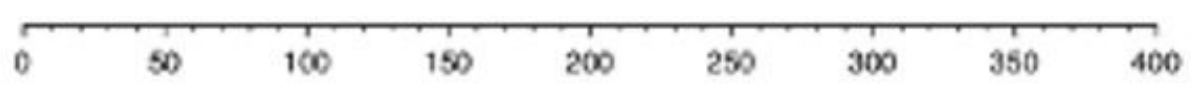

late-rocurrence Risk

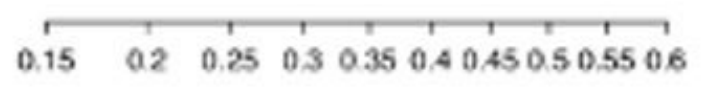

\section{Figure 5}

Nomogram $\bowtie$. Age at initial diagnosis, hormonal status at initial diagnosis, treatment mode, type of surgery, positive lymph nodes, neo-/adjuvant chemotherapy, neo-/adjuvant endocrine therapy and adjuvant radiotherapy were used to construct logistic regression-based nomogram $\otimes$. 


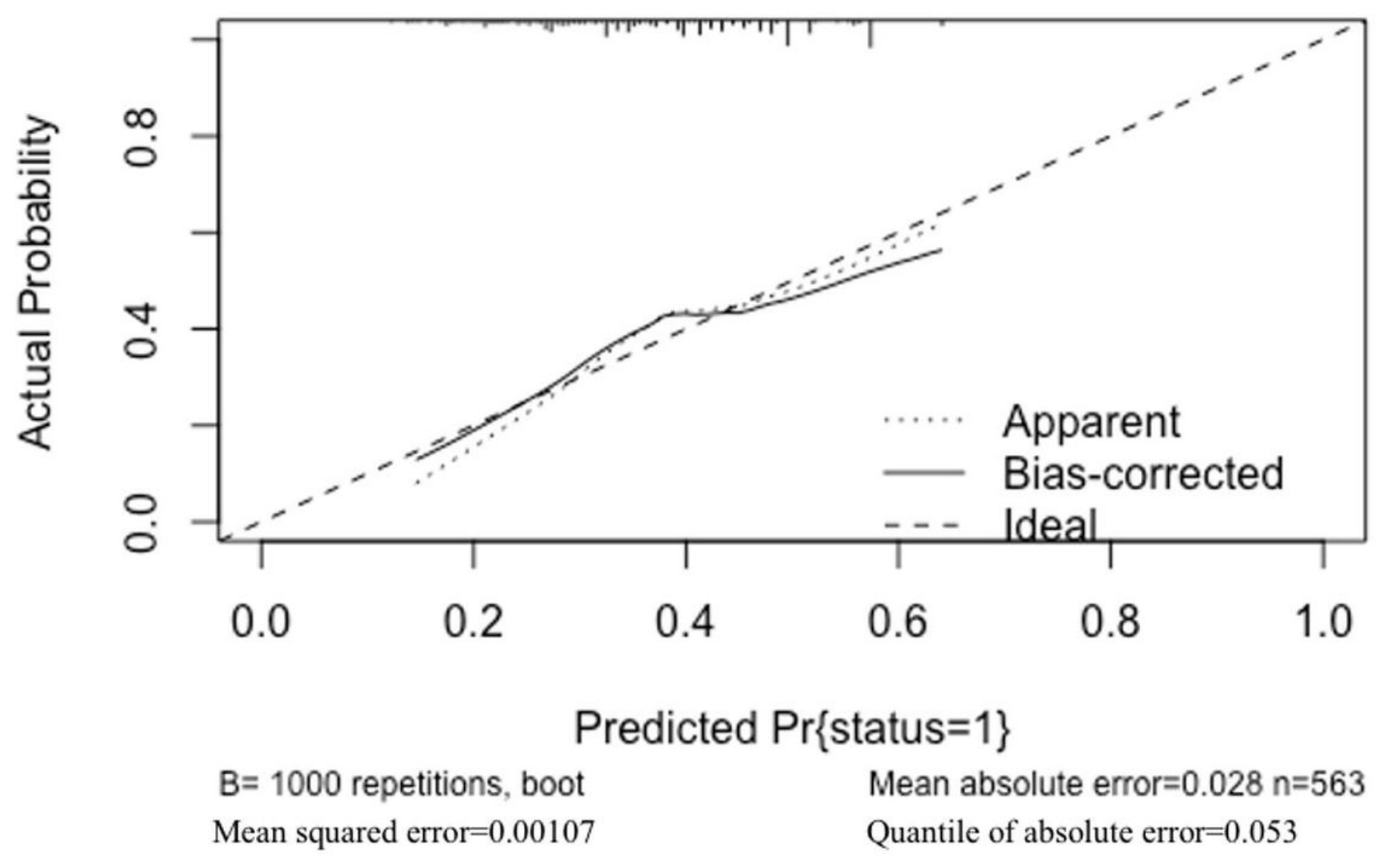

Figure 6

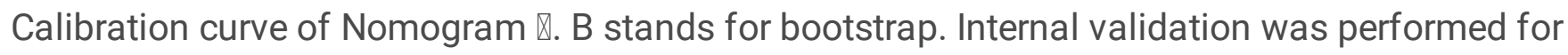
Nomogram $\otimes$ using bootstrap resampling method, and calibration curve was depicted as above. In internal validation, 1000 repetitions of resampling were carried out. Based on the results of internal validation, calibration curve was depicted. The closer the curve is to the diagonal line, the more reliable the nomogram is. Absolute error and squared error were used to describe difference between predictive value and actual value. The smaller the error is, the more reliable the nomogram is. 
ago

$\geq 50$

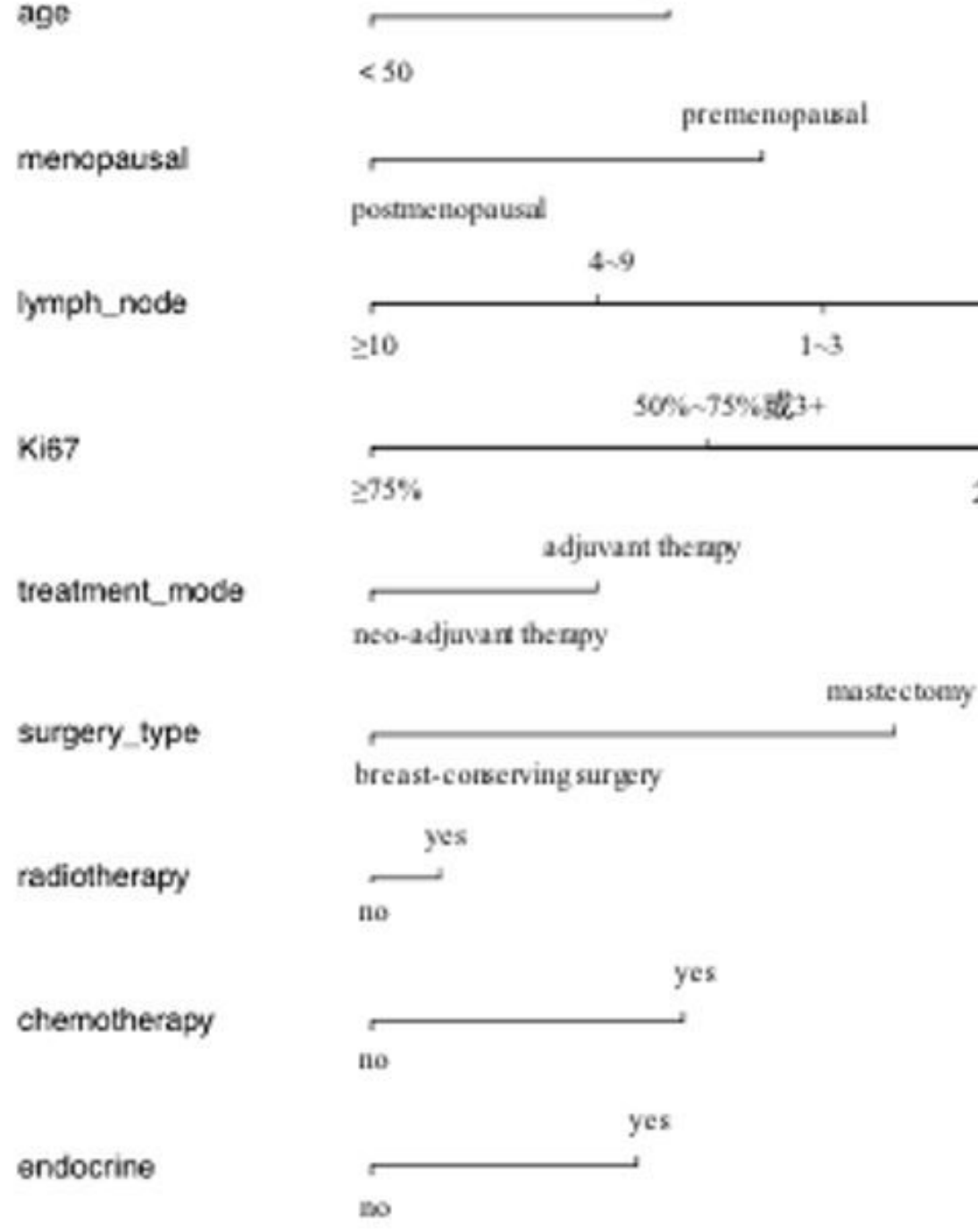

Total Points

\begin{tabular}{|c|c|c|c|c|c|c|}
\hline 50 & 100 & 150 & 200 & 250 & 300 & 400 \\
\hline
\end{tabular}

late-rocurrence Risk

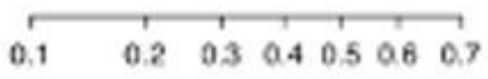

\section{Figure 7}

Nomogram $\otimes$. Age at initial diagnosis, hormonal status at initial diagnosis, treatment mode, type of surgery, positive lymph nodes, level of Ki-67, neo-/adjuvant chemotherapy, neo-/adjuvant endocrine therapy and adjuvant radiotherapy were used to construct logistic regression-based nomogram $\Downarrow$. 


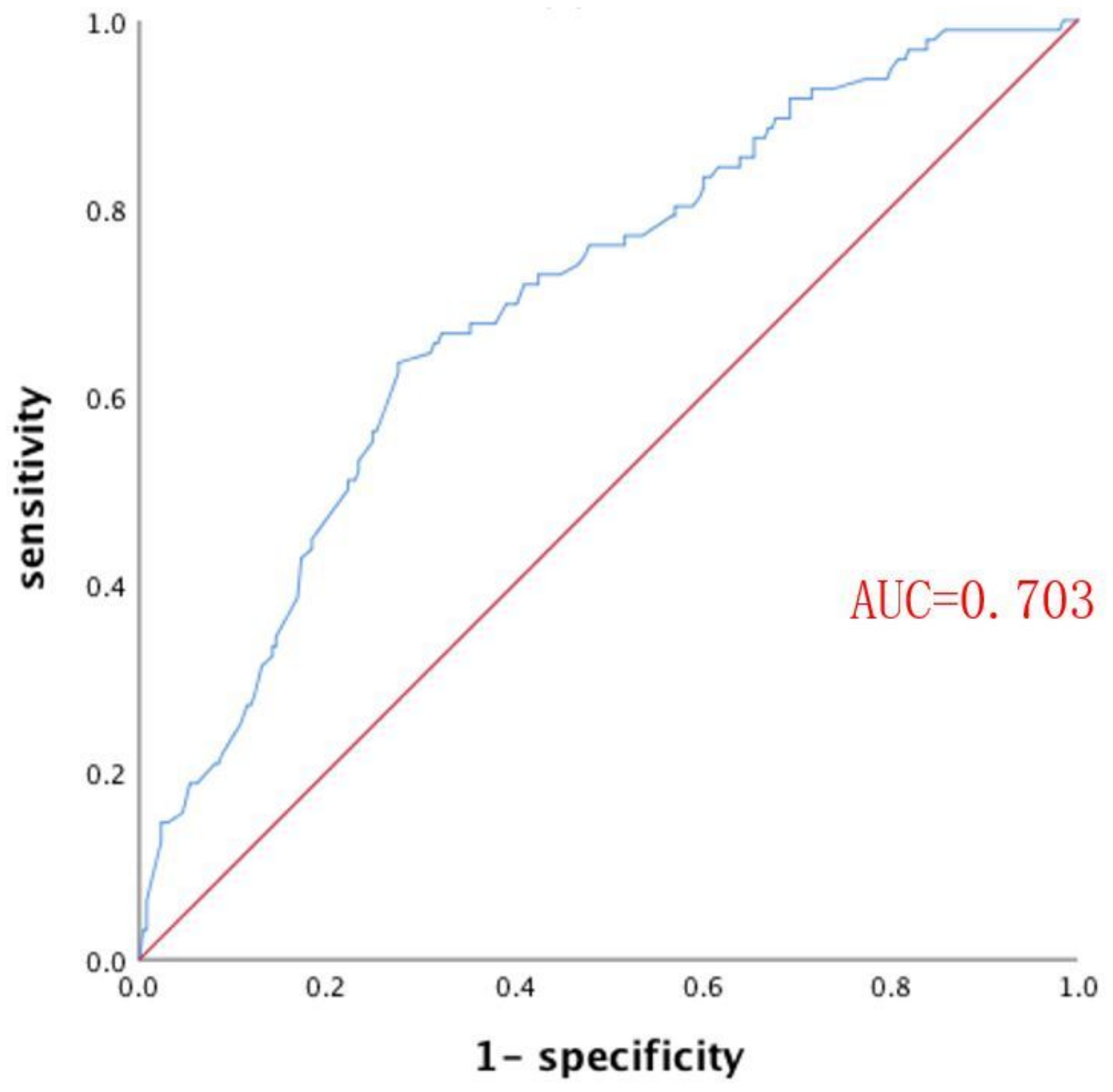

Figure 8

ROC curve of Nomogram $\rrbracket$. ROC curve was depicted to examine the reliability of Nomogram $\rrbracket$. Area under ROC curve (AUC) was 0.703 which showed good discrimination ability of the model. 

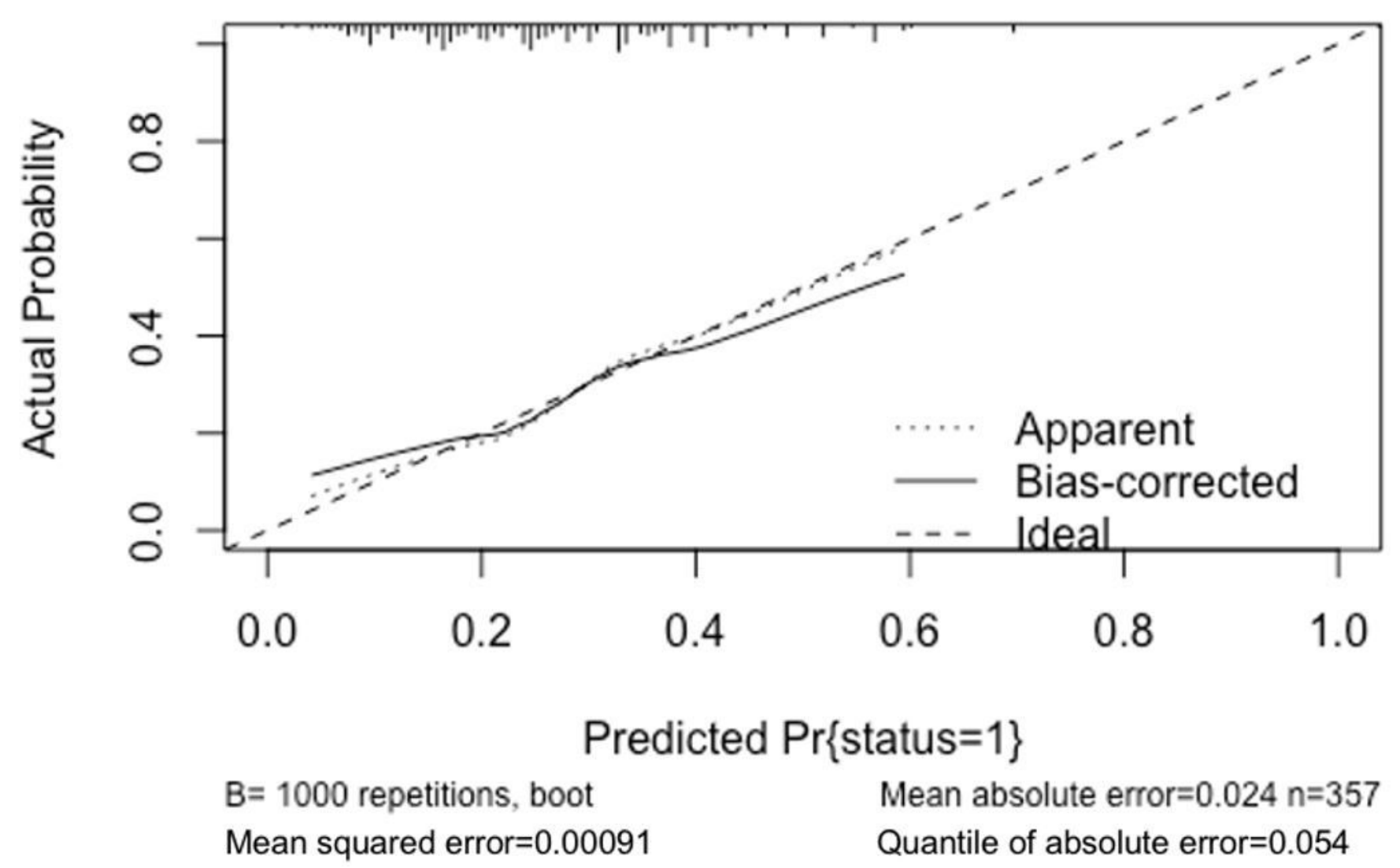

Figure 9

Calibration curve of Nomogram $\otimes$. B stands for bootstrap. Internal validation was performed for Nomogram $\otimes$ using bootstrap resampling method, and calibration curve was depicted as above. In internal validation, 1000 repetitions of resampling were carried out. Based on the results of internal validation, calibration curve was depicted. The closer the curve is to the diagonal line, the more reliable the nomogram is. Absolute error and squared error were used to describe difference between predictive value and actual value. The smaller the error is, the more reliable the nomogram is. 